\title{
Pharmacokinetics and tissue distribution of monotropein and deacetyl asperulosidic acid after oral administration of extracts from Morinda officinalis root in rats
}

Yi Shen ${ }^{1,2}$, Qi Zhang ${ }^{1,2}$, Yan-bin Wu' , Yu-qiong He ${ }^{3}$, Ting Han ${ }^{3}$, Jian-hua Zhang ${ }^{3}$, Liang Zhao ${ }^{4}$, Hsien-yeh Hsu ${ }^{5}$, Hong-tao Song ${ }^{6}$, Bing Lin ${ }^{6}$, Hai-liang Xin ${ }^{3^{*}}$, Yun-peng Qi ${ }^{3^{*}}$ and Qiao-yan Zhang ${ }^{1,2,3^{*}}$ (D)

\begin{abstract}
Background: Iridoid glycosides (IGs), including monotropein (MON) and deacetyl asperulosidic acid (DA) as the main ingredients, are the major chemical components in Morinda officinalis How. (MO) root, possessing various pharmacological properties including anti-osteoporosis, anti-inflammation and anti-rheumatism activities. The aim of the present study was to further elucidate the pharmacological actions of $\mathrm{MO}$ by investigating the pharmacokinetics and tissue distribution of IGs in MO.

Methods: An ultra high performance liquid chromatography-tandem mass spectrometry (UHPLC-MS) method was developed and validated for simultaneous determination of MON and DA levels in plasma and various tissues of Wistar rats. MON, DA and acetaminophen (ACE) as the internal standard (IS) were extracted from rat plasma and tissue samples by direct deproteinization with methanol. The rats were administered orally at $1650 \mathrm{mg} / \mathrm{kg} \mathrm{MO}$ and 25, 50 and $100 \mathrm{mg} / \mathrm{kg} \mathrm{MO}$ iridoid glycosides (MOIGs) or intravenously at MOIG $25 \mathrm{mg} / \mathrm{kg}$ for pharmacokinetic study of MON and DA. In addition, $100 \mathrm{mg} / \mathrm{kg} \mathrm{MOIG}$ was administered orally for tissue distribution study of MON and DA. Non-compartmental pharmacokinetic profiles were constructed. Tissue distributions were calculated according to the validated methods.
\end{abstract}

Results: Significant differences in the pharmacokinetic parameters were observed in male and female rats. The $A \cup C_{0-t}, C_{\max }$ and bioavailability of MON and DA in female rats were higher than those in male rats. MON and DA mainly distributed in the intestine and stomach after oral administration, and noteworthily high concentrations of MON and DA were detected in the rat hypothalamus.

Conclusion: The results of the present study may shed new lights on the biological behavior of MOIGs in vivo, help explain their pharmacological actions, and provide experimental clues for rational clinical use of these IGs extracted from the $\mathrm{MO}$ root.

Keywords: Morinda officinalis, Iridoid glycosides, Pharmacokinetics, Tissue distribution, UPLC-MS/MS

\footnotetext{
* Correspondence: hailiangxin@163.com; qiyunpeng@hotmail.com; zqy1965@163.com

${ }^{3}$ School of Pharmacy, Second Military Medical University, No. 325 Guohe Road, Yangpu District, Shanghai 200433, People's Republic of China

${ }^{1}$ School of Pharmacy, Fujian University of Traditional Chinese Medicine, No. 1

Qiuyang Road, Shangjie Town, Minhou County, Fuzhou 350122, People's

Republic of China

Full list of author information is available at the end of the article
}

(c) The Author(s). 2018 Open Access This article is distributed under the terms of the Creative Commons Attribution 4.0 International License (http://creativecommons.org/licenses/by/4.0/), which permits unrestricted use, distribution, and reproduction in any medium, provided you give appropriate credit to the original author(s) and the source, provide a link to the Creative Commons license, and indicate if changes were made. The Creative Commons Public Domain Dedication waiver (http://creativecommons.org/publicdomain/zero/1.0/) applies to the data made available in this article, unless otherwise stated. 


\section{Background}

The root of Morinda officinalis How (MO), also named as "Bajitian" in traditional Chinese medicine [1], has long been used as a tonic or nutrient supplement to prevent and treat multiple diseases including osteoporosis, depression, rheumatoid arthritis, impotence and Alzheimer disease in China, South Korea, Japan and Southeast Asia [2-6]. These pharmacological properties are believed to be mainly attributed to oligosaccharides, polysaccharides, iridoid glucosides, antharaquinines and volatile oil as the main chemical constituents in the MO root [7-9]. Monotropein (MON) and deacetyl asperulosidic acid (DA), the two major MO iridoid glycosides (MOIGs), accounts for more than $2 \%$ in the root of MO. Previous investigations showed that MON possessed anti-nociceptive, anti-inflammatory and anti-osteoporotic activities [3, 8, 10-12]. For example, MON could protect against chondrocyte apoptosis and catabolism induced by Interleukin $1 \beta$ (IL-1 $\beta$ ), and improve inflammatory medium of RAW 264.7 macrophages and dextran sulfate sodium (DSS)-induced colitis via the NF-kB pathway $[11,12]$. In our previous work on chemical compounds of the $\mathrm{MO}$ root [13], we extracted MOIGs from the MO root by using an optimal technical method and found that content of MON and DA was greater than $60 \%$, suggesting potential therapeutic applications of MOIGs in the treatment of inflammatory and bone diseases such as osteoarthritis, rheumatoid arthritis and inflammatory bone loss.

Some recent studies [14, 15] used a new LC-MS/MS method to determine the plasma concentrations of MON and DA for pharmacokinetic study in rats. However, there are scant studies to describe the absorption properties, tissue distribution and oral bioavailability of MON and DA in vivo, and there is little knowledge about the pharmacokinetics and target organs/tissues of these two compounds. The primary goal of this study is to clarify the in vivo distribution and action mechanism of the two compounds by analyzing the pharmacokinetics and tissue distribution. Firstly, MON and DA levels in the plasma and tissue of Wistar rats were simultaneously detected by using ultra high performance liquid chromatography-tandem mass spectrometry (UHPLC-MS), knowing that it is a simple, rapid and reliable assay. Secondly, the pharmacokinetic, tissue distribution and bioavailability of MON and DA were determined in both sexes of Wistar rats after oral and intravenous administration of MOIG and MO ethanol extracts, hoping that the results could provide useful information for the research and development of IGs extracted from the MO root.

\section{Methods}

\section{Chemicals, reagents and animals}

MON and DA were purchased from Shanghai Yuanye Biological Technology Co., Ltd. The purity was more than $98 \%$, and their chemical structures were verified by NMR, MS and HPLC. ACE $\left(\mathrm{C}_{8} \mathrm{H}_{9} \mathrm{NO}_{2}\right.$, purity $\left.>98 \%\right)$ purchased from the National Institute for the Control of Pharmaceutical and Biological Products (Beijing, China) was used as internal standard (IS). The chemical structures for MON, DA and ACE are shown in Fig. 1. HPLC grade acetonitrile, methanol and formic acid were obtained from Merck Company (Darmstadt, Germany). All the other reagents were of analytical-grade purity, and purchased from Sinopharm Chemical Reagent Co. Ltd. Deionized water was generated by a Milli-Q system from Millipore (Milford, MA, USA).

The MO root was collected from Zhangzhou of Fujian Province of China in October 2017, and identified by Professor Qiao-yan Zhang of the Department of Pharmacognosy, the Second Military Medical University School of Pharmacy (Shanghai, China). The voucher specimen (MO 20171008) was deposited in the herbarium of this Department. MOIG and $\mathrm{MO}$ ethanol extracts were prepared in our laboratory. Briefly, $2.0 \mathrm{~kg}$ powder $\mathrm{MO}$ root was extracted under permeation with $32.0 \mathrm{~L}$ solution of ethanol-water $(70: 30, v / \mathrm{v})$ for $20 \mathrm{~h}$, and then filtrated. The combined filtrate was concentrated under reduced pressure to obtain the MO extract. Then, the MO extract was diluted with water to obtain $1.0 \mathrm{~g}$ crud drug $/ \mathrm{mL}$ working solution. The MO extract $(1.0 \mathrm{~g}$ crud drugs $/ \mathrm{mL}$ ) was adsorbed to XDA-1 macroporous adsorption resin, and eluted with water and 10\% ethanol. The $10 \%$ ethanol elute collected was centrifuged to obtain MOIGs. The yield of MOIGs was $2.4 \%$, and the content of MON and DA in MOIGs was $38.6 \%$ and $23.6 \%$, respectively. The content of MON and DA in the MO extract was $1.27 \%$ and $0.65 \%$, respectively.

Thirty-six male and 36 female healthy Wistar rats (200-220 g) aged 8 weeks were purchased from Sippur Will Kay Company and housed at the Experimental Animal Center of the Second Military Medical University (Certificate No. SCXK 2013-0016). The rats were acclimatized for a week on a $12 \mathrm{~h}$ light-dark cycle under a temperature of $24 \pm 0.5{ }^{\circ} \mathrm{C}$ and humidity of $47.5 \pm 2.5 \%$ before drug administration. All animals were fasted for $12 \mathrm{~h}$ before initiation of the experiment, with free access to water during the course of the experiment.

\section{UHPLC-MS/MS equipment and method}

An Agilent series 1290 UHPLC system (Agilent, USA) was used in this study. An Agilent $\mathrm{ACE} \mathrm{C}_{18}$-PFP column $(3.0 \times 150 \mathrm{~mm}, 3.0 \mu \mathrm{m})$ was used as the stationary phase and the column temperature was maintained at $35{ }^{\circ} \mathrm{C}$. The mobile phase (A) was methanol containing $0.1 \%$ formic acid and $5 \mathrm{mM}$ ammonium formate, and mobile phase (B) was water containing $0.1 \%$ formic acid and $5 \mathrm{mM}$ ammonium formate. The program of gradient elution was as follows: $6 \% \mathrm{~B}$ phase at $0-2 \mathrm{~min}, 6-$ $60 \% \mathrm{~B}$ at $2-3 \mathrm{~min}, 60-60 \% \mathrm{~B}$ at $3-6 \mathrm{~min}$ with a flow rate of $0.4 \mathrm{~mL} / \mathrm{min}$. The auto-sampler was conditioned at $4{ }^{\circ} \mathrm{C}$ and the injection volume was $1 \mu \mathrm{L}$. 


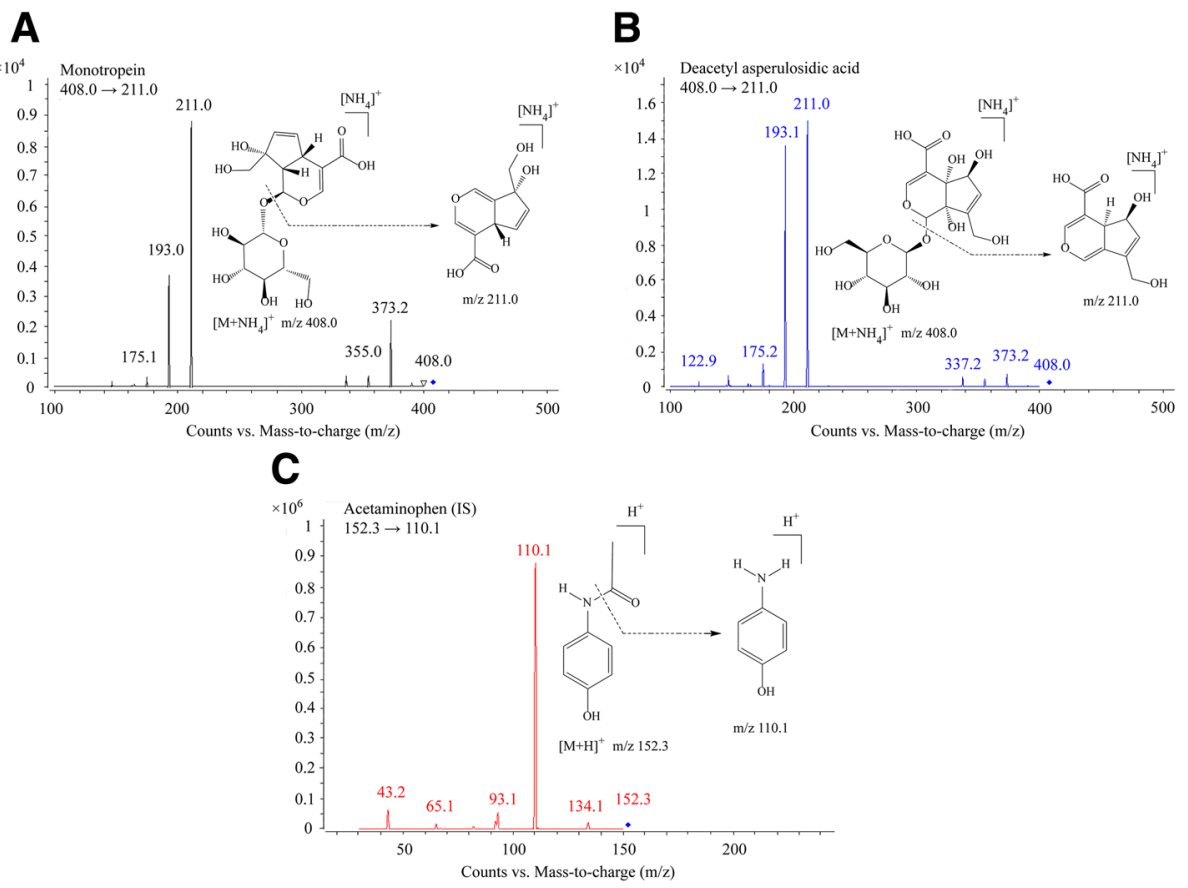

Fig. 1 Product ions and structures of MON (a), DA (b), and IS (c)

The MS detector was composed of an Agilent 6470 tandem mass spectrometer (Agilent technologies, USA) combined with an Agilent Jet Stream Technology (AJS) electrospray source interface (ESI). The mass spectrometric detection was optimized in the positive ion detection mode by multiple reaction monitoring (MRM). The main working parameters of the mass spectrometer are summarized as follows: capillary $4000 \mathrm{~V}$, nebulizer 40 p.s.i., drying gas $10 \mathrm{~L} / \mathrm{min}$, gas temperature $350{ }^{\circ} \mathrm{C}$ and fragmentor $110 \mathrm{~V}$ for analyte and IS, sheath gas temperature $350{ }^{\circ} \mathrm{C}$, sheath gas flow $11 \mathrm{~L} / \mathrm{min}$, collosion energy $10 \mathrm{eV}$ for analyte and $20 \mathrm{eV}$ for IS, fragmentation transitions were $\mathrm{m} / \mathrm{z} 408 \rightarrow 211$ for analyte and $\mathrm{m} / \mathrm{z} 152.3 \rightarrow 110.1$ for IS. Data acquisition and analysis were performed using Agilent Mass Hunter Work Station version B.07.00.

\section{Preparation of calibration standards and quality control samples}

Stock solutions $(1.0 \mathrm{mg} / \mathrm{mL})$ of $\mathrm{MON}$ and DA were prepared in water. The two standard stock solutions were mixed at a high concentration. The mixed solutions were diluted with methanol to obtain the final linearity concentrations of $2-5000 \mathrm{ng} / \mathrm{mL}$ for $\mathrm{MON}$ and DA, respectively. The IS stock solution $(1.0 \mathrm{mg} / \mathrm{mL})$ was also prepared in methanol and diluted to a final working concentration of $10 \mathrm{ng} / \mathrm{mL}$. Quality control (QC) samples were also prepared similarly at the concentrations of 5, 1000 and $4000 \mathrm{ng} / \mathrm{mL}$. All working solutions were stored at $4{ }^{\circ} \mathrm{C}$ before use.

\section{Sample preparation}

The plasma or tissue homogenate was thawed to room temperature $25^{\circ} \mathrm{C} .50 \mu \mathrm{L}$ plasma or tissue homogenate with $100 \mu \mathrm{L}$ IS solution $(10 \mathrm{ng} / \mathrm{mL})$ and $50 \mu \mathrm{L}$ methanol were added into an $1.5 \mathrm{~mL}$ eppendorf tube, and mixed using vortex for $30 \mathrm{~s}$. The mixture was centrifuged $(11,000 \times \mathrm{g})$ at $4{ }^{\circ} \mathrm{C}$ for $10 \mathrm{~min}$. Then, $100 \mu \mathrm{L}$ of the supernatant was transferred into the sample bottle and $1 \mu \mathrm{L}$ of the supernatant was injected into the UHPLC-MS/MS system for analysis.

\section{Method validation}

Linearity, sensitivity, specificity, accuracy, precision, recovery, matrix effect and stability of the method were validated under the guidelines set by the United States of Food and Drug Administration (FDA) [16] and European Medicines Agency (EMA) [17].

\section{Specificity and sensitivity}

The specificity of the method was evaluated by comparing the chromatograms of blank samples (plasma/tissue homogenate) with blank samples spiked with MON, DA, and real samples after oral administration of the $\mathrm{MO}$ extract. Endogenous interference was identified by analyzing six individual blank samples.

\section{Linearity of calibration curves and LLOQ}

Calibration curve samples were prepared in triplicate as previously described and analyzed. The linear curve was generated by plotting the peak area versus the theoretical concentrations of the calibration 
standard. The lower limit of quantification (LLOQ) was defined with a signal-to-noise ratio of 10:1 with precision and accuracy below $20 \%$.

\section{Accuracy and precision}

Three QC samples on the same day $(n=5)$ were detected to evaluate the intra-day precision and accuracy. The inter-day precision and accuracy along with the standard calibration curve $(n=15)$ were determined at the same procedure for 3 consecutive days. The intra-day and inter-day precisions were evaluated by RSD, and the accuracy was evaluated by RE. The accuracy (RE\%) and precision (RSD\%) should be within $\pm 15 \%$.

\section{Extraction recovery and matrix effect}

The extraction recoveries of MON and DA were estimated by comparing the observed peak areas of the prepared QC samples with those of non-processed samples at six replicates. The matrix effect (ME) was evaluated by comparing the peak areas of the post-extracted blank plasma/tissue homogenate samples with those of analytes from neat standard samples at three different QC concentrations.

\section{Stability}

The stability was evaluated by the RE of analysis in plasma samples at three levels of QC during storage and handling conditions: three freeze/thaw cycles, $6 \mathrm{~h}$ stability at room temperature, auto-sampler for $24 \mathrm{~h}$ and storage at $-80{ }^{\circ} \mathrm{C}$ for 30 days. The accuracy (RE) should be below $15 \%$.

\section{Carry-over and dilution}

The upper limit of quantification (ULOQ) was detected by the double-blank sample in order to evaluate carry-over. And the peak area of the double-blank sample should be less than $15 \%$ of LLOQ, while the IS should be lower than $5 \%$.

Dilution integrity was evaluated by diluting the samples with the 10-fold concentration of ULOQ to 10, 20 and $40 \mu \mathrm{g} / \mathrm{mL}$ for the standard plasma by blank samples matrix (dilution has already covered the concentration range of actual samples). And five parallel processing samples of every dilution level were verified. Finally, the accuracy (RE) and precision (RSD) should be below $15 \%$.

\section{Pharmacokinetic study}

All animal treatments in this study were approved by the Administrative Committee of Experimental Animal Care and Use of the Second Military Medical University in accordance with the National Institute of Health guidelines on the ethical use of animals. According to the results of the previous pharmacodynamic experimental study, 30 rats of both sexes were equally randomized to five groups and orally administered with 25, 50 and $100 \mathrm{mg} / \mathrm{kg}$ MOIG and
$1650 \mathrm{mg} / \mathrm{kg} \mathrm{MO}$ extract (the quantities of $\mathrm{MON}$ and DA are equal to those in $50 \mathrm{mg} / \mathrm{kg}$ MOIG) and administered intravenously with $25 \mathrm{mg} / \mathrm{kg}$ MOIG, all of which were dissolved in physiological saline for administration. $0.4 \mathrm{~mL}$ heparinized plasma samples were collected from the ophthalmic venous plexus with a sterile capillary tube at pre-administration (time $=0$ ) and oral post-administration (time $=0.167,0.333,0.5,0.75,1,1.5,2,2.5,3,5,7,10$ and $24 \mathrm{~h}$ ), and intravenous post-administration (time $=0.033$, $0.083,0.167,0.333,0.5,0.75,1,2,3,5,7,10,12$ and $24 \mathrm{~h}$ ), respectively. At the end of the experiment, all rats were sacrificed by cervical dislocation. The samples were timely centrifuged at $11,000 \times \mathrm{g}$ at $4{ }^{\circ} \mathrm{C}$ for $10 \mathrm{~min}$, and then $100 \mu \mathrm{L}$ aliquot of supernatant plasma was transferred into another tube and stored at $-20^{\circ} \mathrm{C}$ until analysis.

\section{Tissue distribution study}

Forty-two rats of both sexes were randomized to seven groups and orally administered with $100 \mathrm{mg} / \mathrm{kg}$ MOIG. The rats were sacrificed by cervical dislocation, and various kinds of tissue samples, including the small intestine, large intestine, stomach, spleen, ovary, uterus, heart, kidney, marrow, liver, lung, thymus, hypothalamus and testis were collected at $0.5,1,2,4,8,12$ and $24 \mathrm{~h}$ (6 rats at each time point) and washed with normal saline solution, blotted on filter paper, and then weighed. The tissue samples were homogenized with 10 times of the normal saline solution $(w / v)$. Then the homogenates were centrifuged at $11,000 \times \mathrm{g}$ at $4{ }^{\circ} \mathrm{C}$ for $10 \mathrm{~min}$, then $1.0 \mathrm{~mL}$ aliquot of supernatant homogenates was transferred into another tube and stored at $-20^{\circ} \mathrm{C}$ until analysis.

\section{Data analysis}

The pharmacokinetic parameters, including area under the plasma concentration-time curve $\left(\mathrm{AUC}_{0-\mathrm{t}}\right)$, the area under the plasma concentration-time curve from zero to time infinity $\left(\mathrm{AUC}_{0-\infty}\right)$, mean residence time (MRT), half-life $\left(\mathrm{t}_{1 / 2}\right)$, peak time $\left(\mathrm{T}_{\max }\right)$, peak concentration $\left(\mathrm{C}_{\max }\right)$, body clearance $(\mathrm{CL})$, and apparent volume of body distribution $\left(\mathrm{V}_{\mathrm{d}}\right)$ were calculated using PK Solver 2.0 of Microsoft Excel under the non-compartmental model. The absolute oral bioavailability $\left(\mathrm{F}_{\text {oral }}\right)$ of MON and DA from MOIG and MO extracts after oral administration was calculated using the following formula:

$$
\mathrm{F}_{\text {oral }}=\left(\mathrm{AUC}_{\text {oral }} \cdot \text { Dose }_{\text {i. v. }}\right) /\left(\mathrm{AUC}_{\text {i. v. }} \cdot \text { Dose }_{\text {oral }}\right) \times 100 \% .
$$

\section{Results}

\section{Method development}

Knowing that it is very important to efficiently eliminate protein and potential interferences in bio-samples before UPLC-MS/MS analysis, the effects of acetonitrile, acetonitrile-methanol $(1: 1, v / \mathrm{v})$ and methanol were evaluated on protein elimination. Finally, methanol was found to be superior to the other solutions and therefore used as the 
precipitation reagent. The matrix effect was between 85 and $110 \%$ for the bio-samples treated with methanol precipitation.

MRM is very powerful for pharmacokinetic study due to high sensitivity, selectivity and specificity. In this work, the predominant ions of $\mathrm{MON}\left(\left[\mathrm{M}+\mathrm{NH}_{4}\right]^{+}\right)$, DA $([\mathrm{M}+$ $\left.\left.\mathrm{NH}_{4}\right]^{+}\right)$and IS $\left([\mathrm{M}+\mathrm{H}]^{+}\right)$in the Q1 spectrum were used as the precursor ion to obtain the product ion spectra. The most sensitive mass transitions were $\mathrm{m} / \mathrm{z} 408 \rightarrow 211$ for MON and DA, and m/z 152.3 $\rightarrow 110.1$ for IS (Fig. 1). The working parameters of MS/MS were optimized to maximize the analyte response. Under these conditions, the retention time was $3.7 \mathrm{~min}(\mathrm{MON}), 4.2 \mathrm{~min}(\mathrm{DA})$, and $5.2 \mathrm{~min}$ (IS) in the real samples, and no endogenous interference was observed in the real samples.

\section{Method validation}

\section{Specificity}

The specificity of the method was determined by comparing the typical chromatograms with UPLC-MS of blank plasma/tissue homogenates, black samples spiked with MON, DA and IS. The actual plasma samples after oral administration of MOIGs are shown in Fig. 2. The retention time of MON, DA and IS was 3.7, 4.2 and $5.2 \mathrm{~min}$, respectively. Due to the high specificity of MRM mode, no significant endogenous interference was observed.

\section{Calibration curve and LLOQ}

A linear regression was used to evaluated the linearity by the $1 /$ concentration $(1 / \mathrm{X})$ weighting analysis in the given concentration ranges of $2-5000 \mathrm{ng} / \mathrm{mL}$ for MON and DA in plasma and tissue samples. The calibration curves, coefficients and linear ranges of MON and DA in plasma and each tissue are listed in Additional file 1: Table S1. The calibration curves for all matrices showed good linearity $(R>0.99)$ over the concentration ranges. The LLOQs of MON and DA were both $2 \mathrm{ng} / \mathrm{mL}$ for plasma and tissue samples, with accuracy less than $20.0 \%$ and the precision within $\pm 15 \%$.

\section{Precision and accuracy}

As shown in Additional file 2: Table S2, the intra-day accuracy ranged from $-9.14 \%$ to $4.28 \%$ for $\mathrm{MON}$ and

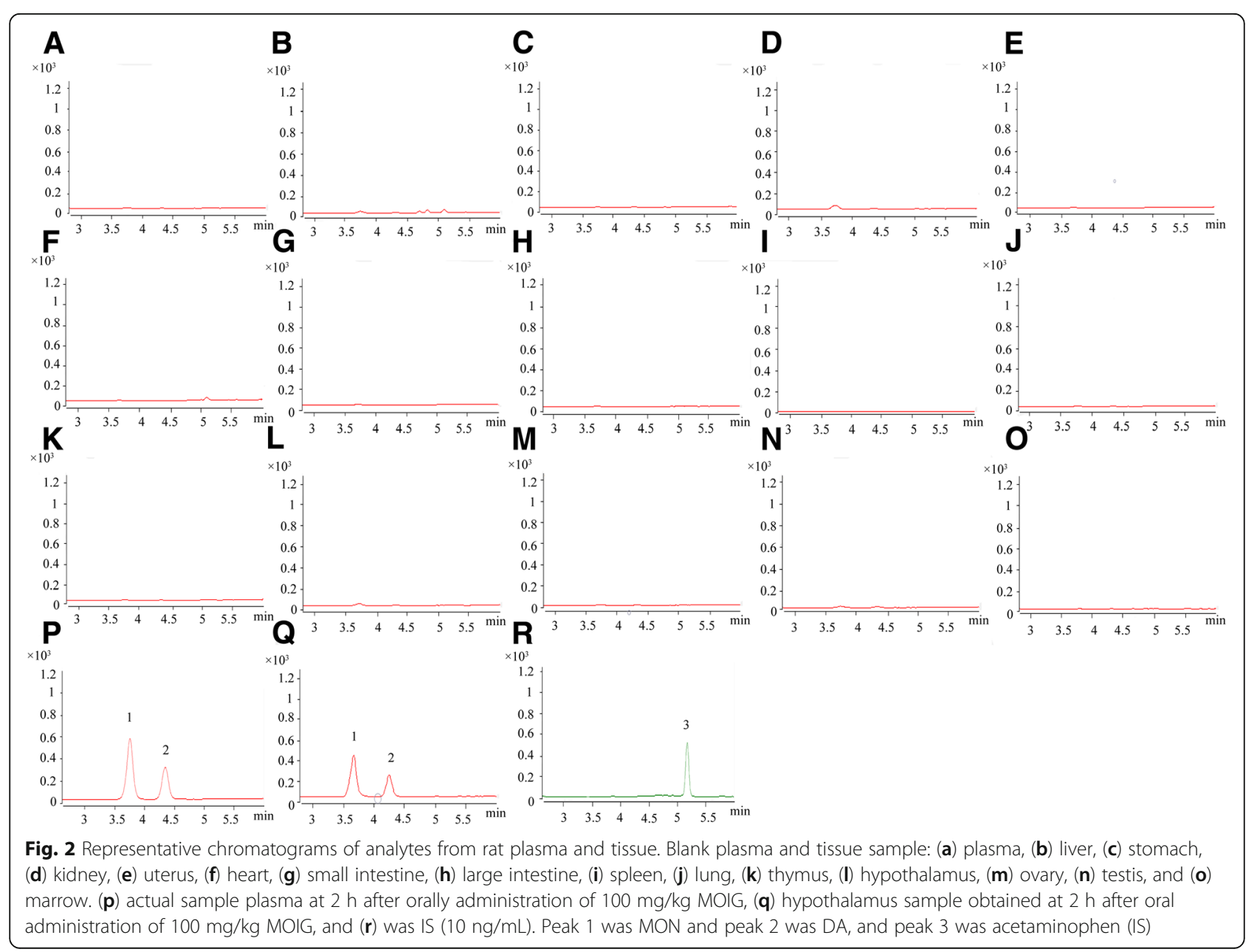


from $-7.72 \%$ to $0.46 \%$ for DA, while the intra-day and inter-day precision were within $9.26 \%$ for $\mathrm{MON}$, and $5.75 \%$ for DA, demonstrating that the assay precision and accuracy of the analysis were within the acceptable range.

\section{Extraction recovery and matrix effect}

As presented in Additional file 3: Table S3, the matrix effect of MON, DA and IS was 85.87-109.26\%, illustrating no significant ion inhibition or enhancement in this method. The extraction recoveries ranged between $62.11-107.42 \%$ for MON, DA and IS, which were also acceptable.

\section{Carry-over and dilution}

No residue was detected in this infinity UHPLC-MS/MS method. The results of the integrity dilution experiment are shown in Additional file 4: Table S4, indicating that the precision was under $10 \%$ and the accuracy was within $\pm 15 \%$, which were also acceptable.

\section{Stability}

The results of the stability test are shown in Additional file 5: Table S5, indicating that MON and DA were stable in the plasma at indoor temperature for $6 \mathrm{~h}$, at $4{ }^{\circ} \mathrm{C}$ in the auto-sampler for $24 \mathrm{~h}$, after three free-thaw cycles, they were kept at $-80{ }^{\circ} \mathrm{C}$ for 30 days.

\section{Pharmacokinetic study}

The mean plasma concentration-time curves are displayed in Fig. 3. The primary pharmacokinetic parameters are enumerated in Tables 1 and 2 . The time from intravenous administration at a dose of $25 \mathrm{mg} / \mathrm{kg}$ MOIG to reaching the maximum concentration $\left(\mathrm{T}_{\max }\right)$ for both $\mathrm{MON}$ and $\mathrm{DA}$ was $0.03 \mathrm{~h}$ in both male and female rats; the maximum plasma concentration $\left(\mathrm{C}_{\max }\right)$ of MON and DA was 39,748 $\pm 3398 \mu \mathrm{g} / \mathrm{mL}$ and $19,126 \pm 1461 \mu \mathrm{g} / \mathrm{mL}$ in male rats, and $25,719 \pm 12,174 \mu \mathrm{g} / \mathrm{mL}$ and $12,340 \pm 5992 \mu \mathrm{g} / \mathrm{mL}$ in female rats, respectively. MON and DA were shown to have a low apparent volume of distribution $\left(\mathrm{V}_{\mathrm{d}}\right.$ from $0.003 \pm 0.002 \mathrm{~L} / \mathrm{g}$

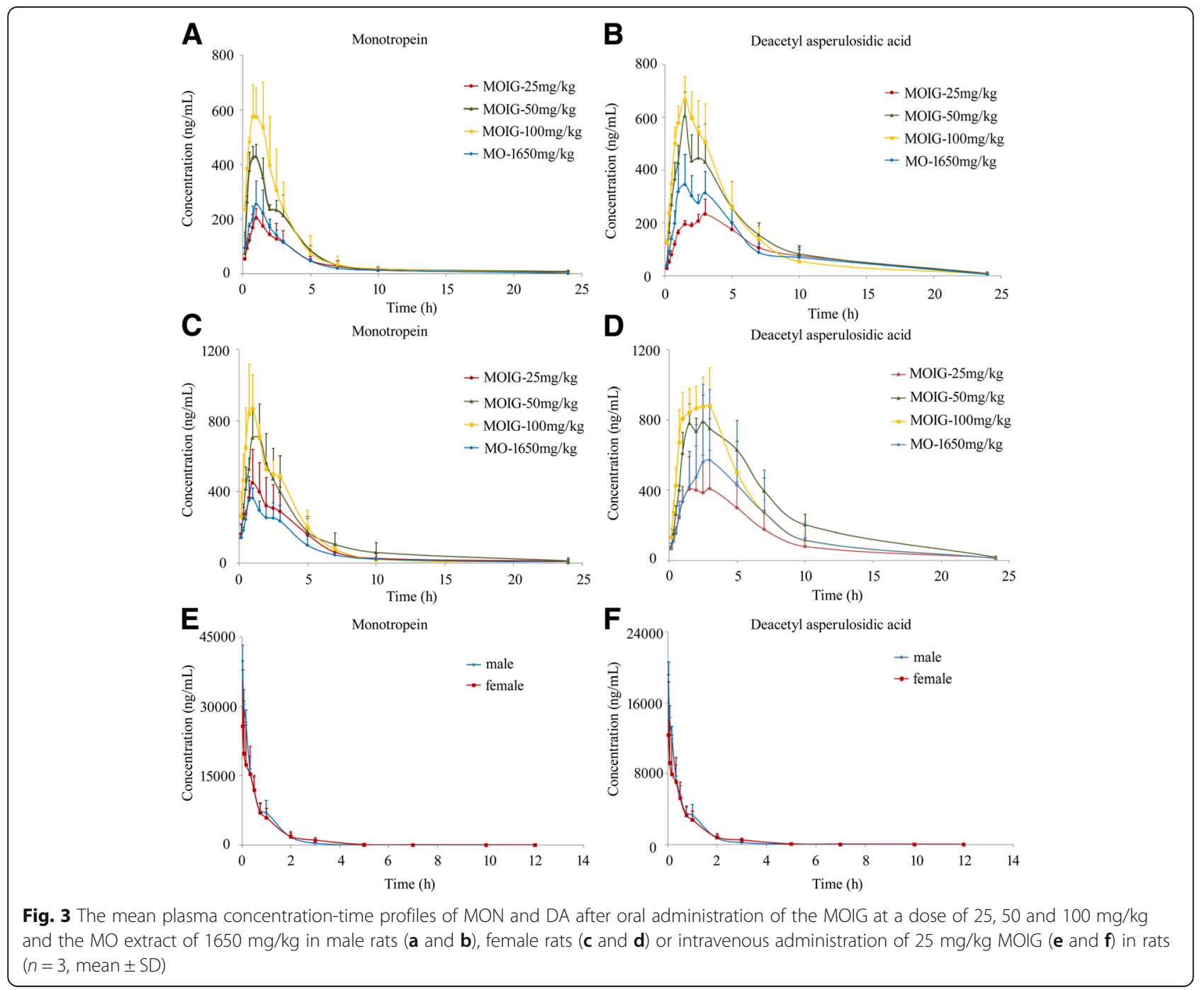


Table 1 The main pharmacokinetic parameters after oral administration of 25, 50, and $100 \mathrm{mg} / \mathrm{kg}$ for MOIG, and $1650 \mathrm{mg} / \mathrm{kg}$ for $\mathrm{MO}$ or intravenous administration of $25 \mathrm{mg} / \mathrm{kg} \mathrm{MOIG}$ in male rats $(n=3$, mean \pm SD)

\begin{tabular}{|c|c|c|c|c|c|c|}
\hline Parameters & Component & po-MOIG-25 & po-MOIG-50 & po-MOIG-100 & po-MO-1650 & iv-MOIG-25 \\
\hline \multirow[t]{2}{*}{$\overline{A \cup C_{0-t}(\mu g \cdot h / L)}$} & MON & $832 \pm 322$ & $1505 \pm 189$ & $1777 \pm 537$ & $875 \pm 182$ & $21,501 \pm 4877$ \\
\hline & DA & $2010 \pm 545$ & $3262 \pm 423$ & $3366 \pm 753$ & $2220 \pm 820$ & $10,239 \pm 2044$ \\
\hline \multirow[t]{2}{*}{$A \cup C_{0-\infty}(\mu g \cdot h / L)$} & MON & $872 \pm 334$ & $1585 \pm 279$ & $1812 \pm 550$ & $877 \pm 182$ & $21,500 \pm 4859$ \\
\hline & DA & $2069 \pm 557$ & $3301 \pm 411$ & $3397 \pm 748$ & $2286 \pm 773$ & $10,239 \pm 2044$ \\
\hline \multirow[t]{2}{*}{$A \cup M C_{0-\infty}(\mu g \cdot h / L)$} & MON & $5121 \pm 2698$ & $8645 \pm 5804$ & $5011 \pm 2132$ & $3064 \pm 882$ & $15,255 \pm 5098$ \\
\hline & DA & $14,739 \pm 5191$ & $17,844 \pm 2090$ & $15,476 \pm 3663$ & $12,867 \pm 5938$ & $8079 \pm 2340$ \\
\hline \multirow[t]{2}{*}{ MRT (h) } & MON & $5.71 \pm 1.96$ & $5.17 \pm 2.58$ & $2.68 \pm 0.40$ & $3.47 \pm 0.43$ & $0.70 \pm 0.09$ \\
\hline & DA & $7.03 \pm 0.68$ & $5.41 \pm 0.24$ & $4.58 \pm 0.15$ & $5.43 \pm 0.94$ & $0.78 \pm 0.09$ \\
\hline \multirow[t]{2}{*}{$t_{1 / 2}(h)$} & MON & $4.60 \pm 1.41$ & $7.11 \pm 2.18$ & $2.76 \pm 1.84$ & $3.00 \pm 0.45$ & $1.85 \pm 1.67$ \\
\hline & DA & $4.80 \pm 0.62$ & $3.80 \pm 1.01$ & $3.76 \pm 0.64$ & $3.65 \pm 1.16$ & $2.90 \pm 0.65$ \\
\hline \multirow[t]{2}{*}{$\mathrm{T}_{\max }(\mathrm{h})$} & MON & $1.00 \pm 0.00$ & $0.92 \pm 0.14$ & $0.92 \pm 0.52$ & $1.17 \pm 0.29$ & $0.03 \pm 0.00$ \\
\hline & DA & $2.33 \pm 0.76$ & $2.00 \pm 0.87$ & $1.5 \pm 0.00$ & $2.17 \pm 0.76$ & $0.03 \pm 0.00$ \\
\hline \multirow[t]{2}{*}{$V_{d}(L / g)$} & MON & $0.20 \pm 0.04$ & $0.32 \pm 0.04$ & $0.22 \pm 0.13$ & $8.51 \pm 2.61$ & $0.004 \pm 0.004$ \\
\hline & DA & $0.09 \pm 0.04$ & $0.08 \pm 0.03$ & $0.17 \pm 0.06$ & $3.90 \pm 0.90$ & $0.011 \pm 0.004$ \\
\hline \multirow[t]{2}{*}{$C L(L / g \cdot h)$} & MON & $0.031 \pm 0.010$ & $0.032 \pm 0.006$ & $0.059 \pm 0.020$ & $1.932 \pm 0.361$ & $0.001 \pm 0.000$ \\
\hline & DA & $0.013 \pm 0.004$ & $0.015 \pm 0.002$ & $0.030 \pm 0.006$ & $0.791 \pm 0.310$ & $0.003 \pm 0.001$ \\
\hline \multirow[t]{2}{*}{$C_{\max }(\mu \mathrm{g} / \mathrm{L})$} & MON & $203 \pm 34$ & $451 \pm 35$ & $605 \pm 114$ & $265 \pm 82$ & $39,748 \pm 3398$ \\
\hline & DA & $236 \pm 54$ & $624 \pm 63$ & $664 \pm 89$ & $379 \pm 91$ & $19,126 \pm 1461$ \\
\hline \multirow[t]{2}{*}{$F(\%)$} & MON & $4.06 \pm 1.55$ & $3.69 \pm 0.65$ & $2.11 \pm 0.64$ & $2.04 \pm 0.42$ & - \\
\hline & DA & $20.21 \pm 5.44$ & $16.12 \pm 2.01$ & $8.29 \pm 1.83$ & $11.16 \pm 3.77$ & - \\
\hline
\end{tabular}

to $0.011 \pm 0.004 \mathrm{~L} / \mathrm{g})$, with a half-life time $\left(\mathrm{t}_{1 / 2}\right)$ from $1.76 \pm$ $1.32 \mathrm{~h}$ to $2.20 \pm 1.86 \mathrm{~h}$ and a clearance from $0.001 \pm 0.000$ to $0.003 \pm 0.001 \mathrm{~L} /(\mathrm{g} \cdot \mathrm{h})$. After oral administration of 3-dose levels of MOIGs, $\mathrm{C}_{\max }$ versus the MON and DA dose distribution was linear with a correlation coefficient being more than 0.90. The increase in $\mathrm{C}_{\max }$ of $\mathrm{MON}$ and DA was positively correlated with the increase in MOIG dosage. The $\mathrm{T}_{\max }$ of MON and DA were observed about $1 \mathrm{~h}$ and $2 \mathrm{~h}$ after oral administration respectively, demonstrating that the blood circulatory system could absorb MON and DA. The value of $T_{\max }$ and $t_{1 / 2}$ demonstrated that $M O N$ and DA were relatively slowly dispersed. Apparent volume of distribution $\left(\mathrm{V}_{\mathrm{d}}\right)$ indicated that $\mathrm{MON}$ and $\mathrm{DA}$ were taken up in the tissue after oral administration, with an absolute bioavailability value of $2.04-3.69 \%$ and $8.29-16.12 \%$ for $\mathrm{MON}$ in male and female rats, and $3.90-10.66 \%$ and 16.17-37.23\% for DA in male and female rats at an oral dose of 25, 50 and $100 \mathrm{mg} / \mathrm{kg}$ MOIG, respectively. These results indicate that the bioavailability of these drugs was dose dependent and showed a significant gender difference.

\section{Tissue distribution study}

Tissue distribution of $\mathrm{MON}$ and DA was investigated in male and female rats at $0.5,1,2,4,8,12$ and $24 \mathrm{~h}$ after oral administration at a dose of $100 \mathrm{mg} / \mathrm{kg}$ MOIG. The level of MON and DA in tissues or organs including the small intestine, large intestine, stomach, spleen, liver, lung, kidney, heart, marrow, thymus, hypothalamus, testis, ovary and uterus was determined. As shown in Tables 3 and 4, MON and DA were widely distributed in all tissues examined after oral administration. MON and DA extensively distributed into the extra-vascular system of the animals. MON and DA levels are significantly reduced to an undetectable level in $12 \mathrm{~h}$ or $24 \mathrm{~h}$ after oral administration. In male rats, the highest concentration of MON and DA was observed in the intestine and stomach, followed by the spleen, heart, kidney, and testis at 1, 2, and $24 \mathrm{~h}$ after oral administration, while the highest concentration of MON and DA in female rats was found in hypothalamus, ovary, uterus, marrow, and liver at 0.5 and $1 \mathrm{~h}$ after oral administration. Apart from the intestine and stomach, the spleen and heart had a higher concentration of MON and DA in the male rats. The concentration of MON and DA in the liver, marrow and hypothalamus was higher in female rats than that in male rats.

\section{Discussion}

It was found in the present study that the same dosage of MON and DA produced significantly different pharmacokinetic parameters in the treatment of po-MOIG-50 and po-MO-1650. Their comparisons were shown in Fig. 4. The $\mathrm{AUC}_{0-\mathrm{t}}, \mathrm{AUC}_{0-\infty}, \mathrm{C}_{\max }$ and absolute bioavailability of $\mathrm{MON}$ and DA in the treatment of po-MO-1650 were lower 
Table 2 The main pharmacokinetic parameters after oral administration of 25, 50, and $100 \mathrm{mg} / \mathrm{kg}$ for MOIG, and $1650 \mathrm{mg} / \mathrm{kg}$ for $\mathrm{MO}$ or intravenous administration of $25 \mathrm{mg} / \mathrm{kg}$ MOIG in female rats $(n=3$, mean $\pm \mathrm{SD}$ )

\begin{tabular}{|c|c|c|c|c|c|c|}
\hline Parameters & Component & po-MOIG-25 & po-MOIG-50 & po-MOIG-100 & po-MO-1650 & iv-MOIG-25 \\
\hline \multirow[t]{2}{*}{$\overline{A \cup C_{0-t}}(\mu g \cdot h / L)$} & MON & $1988 \pm 870$ & $3083 \pm 1184$ & $2963 \pm 397$ & $1504 \pm 244$ & $19,098 \pm 4740$ \\
\hline & DA & $3133 \pm 1580$ & $6572 \pm 884$ & $5727 \pm 992$ & $4254 \pm 3301$ & $8910 \pm 2343$ \\
\hline \multirow[t]{2}{*}{$A \cup C_{0-\infty}(\mu g \cdot h / L)$} & MON & $2040 \pm 815$ & $3178 \pm 1290$ & $2981 \pm 400$ & $1507 \pm 243$ & $19,129 \pm 4743$ \\
\hline & DA & $3221 \pm 1536$ & $6661 \pm 935$ & $5785 \pm 1024$ & $4308 \pm 3367$ & $8945 \pm 2349$ \\
\hline \multirow[t]{2}{*}{$\mathrm{AUMC}_{0-\infty}(\mu \mathrm{g} \cdot \mathrm{h} / \mathrm{L})$} & MON & $10,005 \pm 3510$ & $16,892 \pm 14,358$ & $8895 \pm 1596$ & $5589 \pm 407$ & $17,847 \pm 2842$ \\
\hline & DA & $20,444 \pm 6912$ & $41,101 \pm 9585$ & $29,163 \pm 7495$ & $25,789 \pm 23,049$ & $9214 \pm 715$ \\
\hline \multirow[t]{2}{*}{ MRT (h) } & MON & $5.28 \pm 2.38$ & $4.78 \pm 2.64$ & $2.99 \pm 0.43$ & $3.75 \pm 0.34$ & $0.98 \pm 0.31$ \\
\hline & DA & $6.77 \pm 1.35$ & $6.12 \pm 0.60$ & $4.99 \pm 0.44$ & $5.66 \pm 0.71$ & $1.08 \pm 0.31$ \\
\hline \multirow[t]{2}{*}{$t_{1 / 2}(h)$} & MON & $3.61 \pm 1.03$ & $4.01 \pm 2.35$ & $2.08 \pm 0.50$ & $2.51 \pm 0.34$ & $1.76 \pm 1.32$ \\
\hline & DA & $4.43 \pm 1.12$ & $3.66 \pm 0.35$ & $3.64 \pm 0.43$ & $3.38 \pm 0.44$ & $2.20 \pm 1.86$ \\
\hline \multirow[t]{2}{*}{$T_{\max }(h)$} & MON & $0.94 \pm 0.00$ & $1.33 \pm 0.29$ & $0.92 \pm 0.14$ & $0.92 \pm 0.14$ & $0.03 \pm 0.00$ \\
\hline & DA & $2.17 \pm 0.76$ & $1.83 \pm 0.58$ & $2.33 \pm 0.58$ & $2.08 \pm 1.18$ & $0.03 \pm 0.00$ \\
\hline \multirow[t]{2}{*}{$V_{d}(L / g)$} & MON & $0.08 \pm 0.05$ & $0.09 \pm 0.04$ & $0.10 \pm 0.04$ & $4.07 \pm 1.16$ & $0.003 \pm 0.002$ \\
\hline & DA & $0.07 \pm 0.06$ & $0.04 \pm 0.01$ & $0.09 \pm 0.01$ & $2.50 \pm 1.25$ & $0.009 \pm 0.006$ \\
\hline \multirow[t]{2}{*}{$C L(L / g \cdot h)$} & MON & $0.014 \pm 0.005$ & $0.018 \pm 0.009$ & $0.034 \pm 0.05$ & $1.114 \pm 0.183$ & $0.001 \pm 0.000$ \\
\hline & DA & $0.010 \pm 0.006$ & $0.008 \pm 0.001$ & $0.018 \pm 0.003$ & $0.532 \pm 0.287$ & $0.003 \pm 0.001$ \\
\hline \multirow[t]{2}{*}{$C_{\max }(\mu \mathrm{g} / \mathrm{L})$} & MON & $475 \pm 160$ & $761 \pm 184$ & $899 \pm 197$ & $405 \pm 102$ & $25,719 \pm 12,174$ \\
\hline & $\mathrm{DA}$ & $445 \pm 218$ & $863 \pm 112$ & $966 \pm 171$ & $584 \pm 419$ & $12,340 \pm 5992$ \\
\hline \multirow[t]{2}{*}{$F(\%)$} & MON & $10.66 \pm 4.26$ & $8.31 \pm 3.37$ & $3.90 \pm 0.52$ & $3.94 \pm 0.64$ & - \\
\hline & DA & $36.01 \pm 17.17$ & $37.23 \pm 5.23$ & $16.17 \pm 2.86$ & $24.08 \pm 18.82$ & - \\
\hline
\end{tabular}

than those in the treatment of po-MOIG-50; the $\mathrm{V}_{\mathrm{d}}$ and CL of MON and DA in the treatment of po-MO- 1650 were by far higher than those in the treatment of po-MOIG-50. These results suggest that MON and DA were eliminated more quickly and distributed in the tissue under the condition of coexistence of multicomponents in MO-1650.

It was reported that gender was a potential factor affecting drug pharmacokinetics [18], including the absorption process, distribution and bioavailability. The present study showed that the pharmacokinetic parameters for male and female rats were significantly different. The $\mathrm{AUC}_{0-\mathrm{t}}, \mathrm{C}_{\max }$ and bioavailability of $\mathrm{MON}$ and DA in female rats were higher than those in male rats, but $\mathrm{V}_{\mathrm{d}}$ and $\mathrm{CL}$ of MON and DA in female rats were lower than those in male rats, indicating that MON and DA were cleared more slowly in female rats than those in male rats.

MON and DA are isomers. Some studies $[18,19]$ demonstrated that MON and DA were relatively stable in the MO root under normal conditions, while MON may convert to DA in acidic conditions. This may be the reason for the lower bioavailability of MON than DA. In addition, the concentration-time curve of DA showed an obvious double-peak phenomenon. This might be caused by different absorption capacities in different regions of the gut or enterohepatic circulation [20], the conversion of MON or its derivatives into DA through the hydration in gastric acid conditions [17, 18], the pharmacological effect of the MON and DA [21], and gastric emptying-limited absorption [22].

However, we found that MON and DA also distributed in the hypothalamus, implying that they could pass through the blood-brain barrier. The samples collected at $12 \mathrm{~h}$ after administration indicated that MON and DA were gradually cleared and no accumulation was observed in the tissues. The compounds absorbed through the blood were transported to the target tissue, and then the unbound portion of the drug exerted the pharmacological effect. MON and DA distributed in the heart, liver, spleen, lung, kidney, especially in the thymus and bone marrow. Thence, we surmised that MON and DA may be able to exert their pharmacological effects in these target organs. MO strengths kidney-yang and improves spermatogenesis and the reproductive capacity $[23,24]$, which is consistent with our finding that MON and DA distributed in the testes at a high concentration. $\mathrm{MO}$ and MON showed an obvious anti-osteoporosis effect $[10,11]$, which is consistent with our finding that MON and DA were also observed in the ovary, uterus and bone marrow at a high concentration. The high concentration of MON and DA in the intestine may be related to their therapeutic effect against colitis [12]. The highest 
Table 3 The concentrations $(\mathrm{ng} / \mathrm{mL}$ ) of $\mathrm{MON}$ and DA in various tissues after oral administration of $100 \mathrm{mg} / \mathrm{kg} \mathrm{MO} / \mathrm{G}$ in male rats (mean $\pm \mathrm{SD}, n=3$ )

\begin{tabular}{|c|c|c|c|c|c|c|c|c|}
\hline Tissue/organs & Component & $0.5 \mathrm{~h}$ & $1 \mathrm{~h}$ & $2 \mathrm{~h}$ & $4 \mathrm{~h}$ & $8 \mathrm{~h}$ & $12 \mathrm{~h}$ & $24 \mathrm{~h}$ \\
\hline \multirow[t]{2}{*}{ Small intestine } & MON & $162.8 \pm 134.4$ & $19,075.1 \pm 16,724.9$ & $3223.4 \pm 3453.3$ & $69.2 \pm 114.2$ & $24.6 \pm 34.1$ & $45.6 \pm 78.9$ & $0.1 \pm 0.1$ \\
\hline & DA & $132.2 \pm 101.9$ & $13,371.3 \pm 11,978.3$ & $2053.3 \pm 2478.3$ & $495.0 \pm 838.1$ & $110.7 \pm 152.2$ & $124.9 \pm 197.2$ & $4.3 \pm 6.2$ \\
\hline \multirow[t]{2}{*}{ Large intestine } & MON & $706.8 \pm 659.0$ & $924.9 \pm 972.6$ & $576.9 \pm 380.8$ & $66.1 \pm 79.2$ & $58.3 \pm 29.9$ & $18.6 \pm 4.0$ & $1.7 \pm 3.0$ \\
\hline & DA & $2564.7 \pm 3177.5$ & $1928.8 \pm 1640.6$ & $3135.9 \pm 2828.6$ & $1310.0 \pm 2008.0$ & $994.9 \pm 873.6$ & $334.6 \pm 69.8$ & $26.0 \pm 23.5$ \\
\hline \multirow[t]{2}{*}{ Stomach } & MON & $2888.7 \pm 235.2$ & $1052.1 \pm 402.1$ & $364.5 \pm 141.9$ & $11.7 \pm 11.8$ & $91.0 \pm 21.5$ & $12.1 \pm 20.9$ & $1.0 \pm 1.7$ \\
\hline & DA & $2451.1 \pm 638.1$ & $1124.3 \pm 210.2$ & $435.1 \pm 96.7$ & $39.5 \pm 21.6$ & $84.1 \pm 34.5$ & $20.9 \pm 34.5$ & $3.2 \pm 5.5$ \\
\hline \multirow[t]{2}{*}{ Spleen } & MON & $14.6 \pm 9.8$ & $75.2 \pm 71.0$ & $5434.0 \pm 9376.5$ & $66.6 \pm 113.9$ & $4.6 \pm 7.9$ & $0.2 \pm 0.3$ & $49.8 \pm 86.2$ \\
\hline & DA & $14.1 \pm 8.7$ & $58.9 \pm 49.4$ & $3563.4 \pm 6127.5$ & $9.5 \pm 1.9$ & $6.6 \pm 6.1$ & $3.2 \pm 4.6$ & $29.6 \pm 51.2$ \\
\hline \multirow[t]{2}{*}{ Testis } & MON & $18.4 \pm 3.8$ & $16.3 \pm 15.3$ & $56.6 \pm 11.3$ & $188.4 \pm 304.1$ & $304.2 \pm 513.5$ & $0.0 \pm 0.0$ & $0.0 \pm 0.0$ \\
\hline & DA & $17.1 \pm 4.9$ & $79.1 \pm 67.0$ & $69.1 \pm 11.2$ & $24.8 \pm 5.6$ & $221.0 \pm 358.6$ & $0.0 \pm 0.0$ & $0.8 \pm 1.3$ \\
\hline \multirow[t]{2}{*}{ Heart } & MON & $24.3 \pm 10.6$ & $545.5 \pm 908.9$ & $8.9 \pm 1.9$ & $0.0 \pm 0.0$ & $0.2 \pm 0.3$ & $0.0 \pm 0.0$ & $269.2 \pm 466.2$ \\
\hline & DA & $22.7 \pm 7.4$ & $533.2 \pm 856.8$ & $28.9 \pm 0.8$ & $10.0 \pm 1.9$ & $2.2 \pm 1.9$ & $0.0 \pm 0.0$ & $214.3 \pm 371.2$ \\
\hline \multirow[t]{2}{*}{ Kidney } & MON & $48.6 \pm 19.5$ & $147.8 \pm 109.9$ & $30.7 \pm 4.3$ & $17.0 \pm 4.3$ & $3.5 \pm 1.7$ & $4.2 \pm 7.2$ & $0.0 \pm 0.0$ \\
\hline & DA & $91.7 \pm 15.9$ & $303.2 \pm 162.0$ & $220.2 \pm 19.4$ & $202.2 \pm 40.2$ & $66.1 \pm 6.5$ & $31.5 \pm 18.8$ & $2.5 \pm 4.4$ \\
\hline \multirow[t]{2}{*}{ Marrow } & MON & $82.8 \pm 46.8$ & $24.2 \pm 23.6$ & $10.1 \pm 2.9$ & $5.8 \pm 6.6$ & $1.2 \pm 2.0$ & $0.0 \pm 0.0$ & $0.0 \pm 0.0$ \\
\hline & DA & $102.7 \pm 90.0$ & $37.8 \pm 21.0$ & $24.8 \pm 5.1$ & $11.4 \pm 3.3$ & $5.6 \pm 7.0$ & $0.0 \pm 0.0$ & $0.0 \pm 0.0$ \\
\hline \multirow[t]{2}{*}{ Liver } & MON & $15.6 \pm 7.0$ & $26.5 \pm 7.9$ & $20.3 \pm 5.2$ & $10.3 \pm 3.9$ & $12.6 \pm 9.3$ & $20.4 \pm 35.3$ & $0.0 \pm 0.0$ \\
\hline & DA & $17.5 \pm 2.4$ & $46.9 \pm 15.9$ & $52.0 \pm 7.6$ & $35.4 \pm 7.7$ & $20.9 \pm 5.4$ & $22.9 \pm 31.9$ & $0.0 \pm 0.0$ \\
\hline \multirow[t]{2}{*}{ Lung } & MON & $58.9 \pm 29.3$ & $28.7 \pm 23.1$ & $34.7 \pm 13.9$ & $9.5 \pm 6.3$ & $2.0 \pm 0.3$ & $64.3 \pm 96.8$ & $0.0 \pm 0.0$ \\
\hline & DA & $47.5 \pm 23.8$ & $47.1 \pm 8.6$ & $48.5 \pm 10.5$ & $23.9 \pm 2.5$ & $6.4 \pm 0.7$ & $72.4 \pm 116.7$ & $3.9 \pm 6.7$ \\
\hline \multirow[t]{2}{*}{ Thymus } & MON & $16.8 \pm 11.5$ & $11.6 \pm 3.8$ & $13.0 \pm 2.8$ & $13.0 \pm 11.1$ & $6.4 \pm 1.3$ & $0.0 \pm 0.0$ & $0.0 \pm 0.0$ \\
\hline & DA & $22.7 \pm 14.6$ & $23.0 \pm 3.5$ & $29.7 \pm 5.0$ & $10.1 \pm 1.9$ & $4.5 \pm 3.2$ & $0.8 \pm 1.4$ & $1.5 \pm 2.0$ \\
\hline \multirow[t]{2}{*}{ Hypothalamus } & MON & $152.5 \pm 76.3$ & $110.3 \pm 58.0$ & $122.7 \pm 137.7$ & $27.7 \pm 39.7$ & $16.4 \pm 14.2$ & $0.0 \pm 0.0$ & $0.0 \pm 0.0$ \\
\hline & DA & $101.0 \pm 19.9$ & $70.9 \pm 27.6$ & $74.7 \pm 88.3$ & $32.5 \pm 29.7$ & $17.1 \pm 14.9$ & $4.8 \pm 8.3$ & $2.6 \pm 4.6$ \\
\hline
\end{tabular}

concentration of MON and DA in the hypothalamus was observed at $0.5 \mathrm{~h}$, indicating that MON and DA could directly cross the blood-brain barrier and exert their potential pharmacological action on the hypothalamus-gonad system. In addition, the results of tissue distribution of MON and DA maybe implied some new therapeutic areas of MO. The distribution of MON and DA from MO in the stomach, intestine and lung, combined with its anti-inflammatory effects, maybe hint that $\mathrm{MO}$ can be used to prevent and treat inflammatory disease in these organs, such as gastritis, pneumonia and colon cancer.

Regarding the toxicity of the MO, there is no literature to report the adverse effect of MO at a normal dose in clinics. The acute toxicity test indicated that $\mathrm{MO}$ at a cumulative dose of $250 \mathrm{~g} / \mathrm{kg} /$ day did not lead to death of mice in 3 days [25]. Some investigation showed that MO extracts had no mutagenic or genotoxic effect on Escherichia coli PQ37DNA [26]. Our experiments indicated that MOIG at dose of $22.5 \mathrm{~g} / \mathrm{kg}$ did not cause any death of mice. These evidence, together with their significant pharmacological properties, implied that iridoid glycosides, such as monotropein and deacetyl asperulosidic acid from Morinda officinalis root in rats, had potential for the use in medication, especially for inflammatory disease.

\section{Conclusion}

The two major IGs (MON and DA) from the MO root were simultaneously determined by a simple, rapid and sensitive UHPLC-MS/MS method. This method was also used in the study of pharmacokinetics and tissue distribution after oral administration of 25,50 , and $100 \mathrm{mg} / \mathrm{kg}$ MOIGs and $1650 \mathrm{mg} / \mathrm{kg}$ MO extract. This is the first report on the pharmacokinetic and tissue distribution of MON and DA after oral administration of the MO extract. We also found that MON and DA exhibited a significant gender difference in terms of the pharmacokinetic parameters. In addition, the absolute bioavailability of MON and DA also showed a significant gender difference. The results of tissue distribution in male and female rats indicated that MON and DA from the MO root mainly distributed in the intestine and stomach after oral administration, followed by the 
Table 4 The concentrations $(\mathrm{ng} / \mathrm{mL})$ of $\mathrm{MON}$ and DA in various tissues after oral administration of $100 \mathrm{mg} / \mathrm{kg} \mathrm{MOIG}$ in female rats (mean $\pm S D, n=3$ )

\begin{tabular}{|c|c|c|c|c|c|c|c|c|}
\hline Tissue/organs & Component & $0.5 \mathrm{~h}$ & $1 \mathrm{~h}$ & $2 \mathrm{~h}$ & $4 \mathrm{~h}$ & $8 \mathrm{~h}$ & $12 \mathrm{~h}$ & $24 \mathrm{~h}$ \\
\hline \multirow[t]{2}{*}{ Small intestine } & MON & $244.3 \pm 392.8$ & $19,223.7 \pm 9918.4$ & $11,552.4 \pm 18,012.3$ & $5751.1 \pm 4091.9$ & $26.1 \pm 20.4$ & $8.3 \pm 14.4$ & $1.9 \pm 3.2$ \\
\hline & DA & $153.0 \pm 232.2$ & $11,548.8 \pm 3298.3$ & $7897.3 \pm 11,589.7$ & $6001.6 \pm 2129.6$ & $28.3 \pm 10.9$ & $198.7 \pm 310.3$ & $3.0 \pm 5.2$ \\
\hline \multirow[t]{2}{*}{ Large intestine } & MON & $966.5 \pm 1501.4$ & $1089.2 \pm 411.5$ & $2949.1 \pm 4063.5$ & $215.6 \pm 137.4$ & $27.9 \pm 5.8$ & $17.4 \pm 22.5$ & $0.0 \pm 0.0$ \\
\hline & DA & $1408.8 \pm 2274.2$ & $2026.4 \pm 1904.6$ & $5383.1 \pm 4417.7$ & $5200.8 \pm 4470.2$ & $246.3 \pm 189.6$ & $374.1 \pm 418.7$ & $0.4 \pm 0.3$ \\
\hline \multirow[t]{2}{*}{ Stomach } & MON & $1913.2 \pm 1817.5$ & $3098.1 \pm 3293.7$ & $1226.6 \pm 1009.2$ & $39.1 \pm 22.2$ & $81.3 \pm 25.5$ & $0.0 \pm 0.00$ & $0.0 \pm 0.0$ \\
\hline & DA & $1526.7 \pm 1436.1$ & $3015.9 \pm 3232.2$ & $1328.7 \pm 1031.1$ & $83.0 \pm 33.6$ & $73.6 \pm 22.8$ & $1.0 \pm 0.9$ & $0.0 \pm 0.0$ \\
\hline \multirow[t]{2}{*}{ Spleed } & MON & $25.0 \pm 16.2$ & $102.8 \pm 120.3$ & $28.5 \pm 21.9$ & $7.7 \pm 7.1$ & $14.9 \pm 22.5$ & $0.0 \pm 0.0$ & $0.0 \pm 0.0$ \\
\hline & DA & $29.4 \pm 15.7$ & $83.9 \pm 82.6$ & $43.6 \pm 31.6$ & $19.9 \pm 11.5$ & $16.5 \pm 17.7$ & $0.0 \pm 0.0$ & $0.0 \pm 0.0$ \\
\hline \multirow[t]{2}{*}{ Ovary } & MON & $374.7 \pm 318.2$ & $2112.7 \pm 2497.3$ & $504.0 \pm 470.3$ & $138.4 \pm 105.5$ & $45.5 \pm 15.6$ & $6.5 \pm 11.3$ & $1.7 \pm 2.9$ \\
\hline & DA & $241.9 \pm 185.0$ & $854.1 \pm 859.3$ & $382.3 \pm 298.2$ & $110.4 \pm 101.8$ & $33.8 \pm 9.5$ & $5.7 \pm 9.8$ & $0.7 \pm 1.3$ \\
\hline \multirow[t]{2}{*}{ Uterus } & MON & $331.7 \pm 229.3$ & $2214.1 \pm 2264.0$ & $601.3 \pm 664.6$ & $269.9 \pm 217.3$ & $97.2 \pm 21.0$ & $0.0 \pm 0.0$ & $3.0 \pm 5.0$ \\
\hline & DA & $194.0 \pm 122.7$ & $1069.7 \pm 908.8$ & $426.3 \pm 422.7$ & $256.6 \pm 340.3$ & $68.4 \pm 14.9$ & $1.8 \pm 2.1$ & $3.6 \pm 3.5$ \\
\hline \multirow[t]{2}{*}{ Heart } & MON & $44.3 \pm 18.2$ & $79.0 \pm 91.0$ & $21.5 \pm 3.6$ & $5.8 \pm 5.7$ & $3.7 \pm 6.5$ & $0.0 \pm 0.0$ & $0.0 \pm 0.0$ \\
\hline & DA & $45.8 \pm 19.1$ & $86.1 \pm 81.8$ & $42.1 \pm 7.7$ & $17.6 \pm 4.9$ & $6.3 \pm 5.6$ & $0.0 \pm 0.0$ & $0.0 \pm 0.0$ \\
\hline \multirow[t]{2}{*}{ Kidney } & MON & $146.6 \pm 133.3$ & $139.8 \pm 98.6$ & $68.3 \pm 25.4$ & $48.8 \pm 27.5$ & $14.1 \pm 10.3$ & $0.0 \pm 0.0$ & $8.1 \pm 14.0$ \\
\hline & DA & $1832.9 \pm 2990.7$ & $218.6 \pm 114.6$ & $264.8 \pm 33.7$ & $244.0 \pm 25.8$ & $109.0 \pm 22.5$ & $44.6 \pm 2.5$ & $0.9 \pm 1.4$ \\
\hline \multirow[t]{2}{*}{ Marrow } & MON & $583.1 \pm 978.7$ & $257.0 \pm 226.1$ & $48.4 \pm 60.3$ & $10.7 \pm 14.8$ & $0.1 \pm 0.2$ & $0.0 \pm 0.0$ & $0.0 \pm 0.0$ \\
\hline & DA & $446.2 \pm 744.7$ & $209.9 \pm 183.6$ & $66.1 \pm 51.3$ & $27.6 \pm 29.1$ & $3.8 \pm 1.9$ & $0.0 \pm 0.0$ & $0.0 \pm 0.0$ \\
\hline \multirow[t]{2}{*}{ Liver } & MON & $729.3 \pm 993.8$ & $169.0 \pm 129.8$ & $66.4 \pm 23.4$ & $13.9 \pm 4.6$ & $33.0 \pm 36.6$ & $0.0 \pm 0.0$ & $0.0 \pm 0.0$ \\
\hline & DA & $536.2 \pm 725.7$ & $142.0 \pm 83.4$ & $87.2 \pm 13.9$ & $42.2 \pm 12.1$ & $36.3 \pm 14.4$ & $3.1 \pm 3.0$ & $0.0 \pm 0.0$ \\
\hline \multirow[t]{2}{*}{ Lung } & MON & $72.2 \pm 53.3$ & $398.3 \pm 491.2$ & $50.6 \pm 33.7$ & $244.8 \pm 407.7$ & $26.7 \pm 25.6$ & $47.6 \pm 82.5$ & $0.0 \pm 0.0$ \\
\hline & DA & $56.5 \pm 29.8$ & $222.3 \pm 257.4$ & $72.1 \pm 28.2$ & $180.7 \pm 267.3$ & $23.8 \pm 16.9$ & $30.2 \pm 52.3$ & $0.0 \pm 0.0$ \\
\hline \multirow[t]{2}{*}{ Thymus } & MON & $22.3 \pm 9.2$ & $140.0 \pm 144.2$ & $32.6 \pm 36.1$ & $1.8 \pm 1.1$ & $22.8 \pm 6.3$ & $0.0 \pm 0.00$ & $0.0 \pm 0.0$ \\
\hline & DA & $26.50 \pm 7.7$ & $136.05 \pm 128.2$ & $57.3 \pm 45.6$ & $14.1 \pm 3.4$ & $30.6 \pm 8.6$ & $0.0 \pm 0.0$ & $0.0 \pm 0.0$ \\
\hline \multirow[t]{2}{*}{ Hypothalamus } & MON & $2209.3 \pm 3684.2$ & $504.1 \pm 333.9$ & $226.2 \pm 264.4$ & $41.1 \pm 43.2$ & $72.3 \pm 95.2$ & $0.0 \pm 0.0$ & $9.7 \pm 16.9$ \\
\hline & DA & $1754.0 \pm 2942.7$ & $287.1 \pm 176.9$ & $145.8 \pm 144.6$ & $47.2 \pm 9.2$ & $67.7 \pm 77.7$ & $0.0 \pm 0.0$ & $21.0 \pm 36.4$ \\
\hline
\end{tabular}

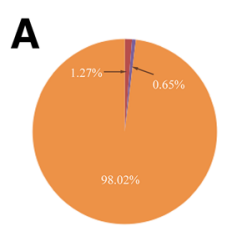

B

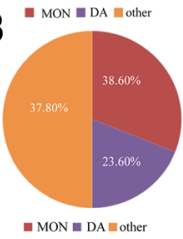

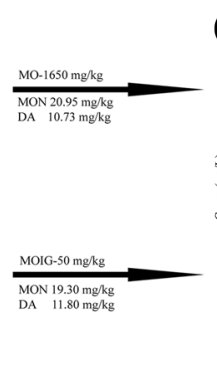
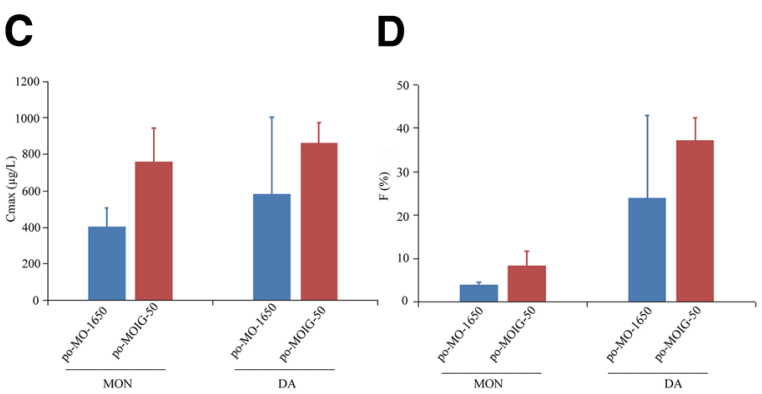

Fig. 4 The pie diagram of actual values of MON and DA in the MO (a) and MOIG (b). After oral administration of the $50 \mathrm{mg} / \mathrm{kg} \mathrm{MOIG}$ and $1650 \mathrm{mg} / \mathrm{kg} \mathrm{MO}$ extract, comparing the $\mathrm{C}_{\max }(\mathbf{c})$ and absolute bioavailability (d) of MON and DA in female rats plasma 
spleen, hypothalamus, and gonad. These findings may shed new lights on the biological behavior of MOIGs in vivo, help explain some of their pharmacological actions, and provide experimental clues for rational clinical use of these IGs extracted from the MO root.

\section{Additional files}

Additional file 1: Table S1. Standard curves, linear ranges, correlation coefficients and lower limit of quantification of MON and DA in biological samples. (DOC $68 \mathrm{~kb}$ )

Additional file 2: Table S2. Intra-day and inter-day accuracy and precision of analytes in rats blank samples. (DOC $19 \mathrm{~kb}$ )

Additional file 3: Table S3. Extraction recovery and matrix effect of MON, DA and IS in rat plasma and tissue homogenates $(n=6$, mean \pm SD). (DOC $83 \mathrm{~kb}$ )

Additional file 4: Table S4. Dilution integrity experiments of MON and DA $(n=5$, mean \pm SD). (DOC $19 \mathrm{~kb})$

Additional file 5: Table S5. Stability of MON and DA in blank plasma samples $(n=5)$. (DOC $19 \mathrm{~kb})$

\section{Abbreviations}

ACE: Acetaminophen; AJS: Agilent jet stream technology; $\mathrm{AUC}_{0-\infty}$ : Area under the plasma concentration-time curve from zero to time infinity; $A \cup C_{0-t}$ : Area under the plasma concentration-time curve; $\mathrm{CL}$ : Body clearance; $\mathrm{C}_{\text {max }}$ : Peak concentration; DA: Deacetyl asperulosidic acid; DSS: Dextran sulfate sodium; EMA: European Medicines Agency; ESI: Electrospray source interface; FDA: Food and Drug Administration; Foral: Absolute oral bioavailability; IGs: Iridoid glycosides; IL-1 $\beta$ : Interleukin-1-beta; IS: Internal standard; LLOQ: Lower limit of quantification; ME: Matrix effect; MO: Morinda officinalis; MOIGs: Morinda officinalis iridoid glycosides; MON: Monotropein; MRM: Multiple reaction monitoring; MRT: Mean residence time; QC: Quality control; $t_{1 / 2}$ : Half-life; $T_{\max }$ : Peak time; UHPLC-MS: Ultra high performance liquid chromatography-tandem mass spectrometry; ULOQ: Upper limit of quantification; $V_{d}$ : Apparent volume of body distribution

\section{Acknowledgements}

We would like to thank the Experimental Animal Center of the Second Military Medical University for providing experimental sites.

\section{Funding}

This study was supported by the National Natural Science Foundation of China (Grant No. U1505226 and U1603283) and Shanghai Committee of Science and Technology (Grant No.14401902700).

\section{Availability of data and materials}

All datasets used and/or analysed during the current study are available from the corresponding author on reasonable request.

\section{Authors' contributions}

SY, ZQY, QYP, and XHL contributed to the study design. HT, HHY, and ZL contributed the reagents, materials and analysis tools. SY, ZQ, HYQ, and ZJH performed the experiments. WYB, SHT, and LB analyzed and interpreted the data. SY, ZQY and QYP wrote and revised the manuscript. All authors read and approved the final manuscript.

\section{Competing interest}

The authors declare that they have no competing interests.

\section{Ethics approval and consent to participate}

All animal protocols were approved by the Experimental Animal Ethic Committee of the Second Military Medical University (No. SMMU-Pharm0004).
Consent for publication

No applicable.

\section{Publisher's Note}

Springer Nature remains neutral with regard to jurisdictional claims in published maps and institutional affiliations.

\section{Author details}

${ }^{1}$ School of Pharmacy, Fujian University of Traditional Chinese Medicine, No. 1 Qiuyang Road, Shangjie Town, Minhou County, Fuzhou 350122, People's Republic of China. ${ }^{2}$ School of Pharmacy, Zhejiang University of Traditional Chinese Medicine, Gaoke Road, Fuyang District, Hangzhou 310053, People's Republic of China. ${ }^{3}$ School of Pharmacy, Second Military Medical University, No. 325 Guohe Road, Yangpu District, Shanghai 200433, People's Republic of China. ${ }^{4}$ Department of Pharmacy, Eastern Hepatobiliary Surgery Hospital, Second Military Medical University, No. 225 Changhai Road, Yangpu District, Shanghai 200438, People's Republic of China. ${ }^{5}$ Department of Biotechnology and Laboratory Science in Medicine, National Yang-Ming University, No. 155, Section 2, Li Nong Street, Beitou District, Taipei 112-21, People's Republic of China. ${ }^{6}$ Fuzhou General Hospital of Nanjing Military Region, No. 156, West Second Ring North Road, Gulou District, Fuzhou 350025, People's Republic of China.

Received: 4 July 2018 Accepted: 12 October 2018

Published online: 24 October 2018

\section{References}

1. Zhang JH, Xin HL, Xu YM, Shen $Y$, He YQ, Hsien $Y$, Ling B, Song HT, Juan L, Yang HY, Qin LP, Zhang QY, Du J. Morinda officinalis how. -Acomprehensive review of traditional uses, phytochemistry and pharmacology. J Ethnopharmacol. 2018;213:230-55.

2. Wang YF, Li YH, Xing SQ, Li Y, Yi LZT, Shang XD, Zhao DF, Bai LQ. Review of experiment research progress in treating deficiency of kidney-yang syndrome by Morinda officinalis how. And its effective components. China J Tradit Chin Med Pharm. 2016;31:5165-7.

3. Ye WH, Gong MJ, Zou ZJ. Metabonomic study of anti-inflammatory effect of Morinda officinalis How on acute inflammation induced by carrageenan. Pharm Clin Chin Mater Med. 2013;3:22-5.

4. Chen DL, Yang X, Yang J, Lai GX, Yong TQ, Tang XC, Shuai O, Zhou GL, Xie YZ, Wu QP. Prebiotic effect of fructooligosaccharides from Morinda officinalis on Alzheimer's disease in rodent models by targeting the microbiota-gut-brain axis. Front Aging Neurosci. 2017;9:403-30.

5. Cheng D, Murtaza G, Ma SY, Li LL, Li XJ, Tian FZ, Zheng JC. LuY. In silico prediction of the anti-depression mechanism of a herbal formula (Tiansi liquid) containing Morinda officinalis and Cuscuta chinensis. Molecules. 2017;22:1614-29.

6. Lee YK, Bang HJ, Oh JB, Whang WK. Bioassay-guided isolated compounds from Morinda officinalis inhibit Alzheimer's disease pathologies. Molecules. 2017;22:1638-49.

7. Chen YB, Xue Z. Study on chemical constituents of Morinda officinalis how. Bull Chin Mat Med. 1987;12:27-9.

8. Choi J, Lee KT, Choi MY, Nam JH, Jung HJ, Park SK, Park HJ. Antinociceptive anti-inflammatory effect of monotropein isolated from the root of Morinda officinalis. Biol Pharm Bull. 2005;28:1915-8.

9. Wang YL, Cui HM, Huang SJ, Li Q, Lei HM. Determination ofmajor iridoid glycosides in Morinda officinalis from different origins and batches by HPLC. J Chin Med Mat. 2011;34:1187-90.

10. Zhang ZG, Zhang QY, Yang H, Liu W, Zhang ND, Qin LP, Xin HL. Monotropeinisolated from the roots of Morinda officinalis increases osteoblastic bone formation and prevents bone loss in ovariectomized mice. Fitoterapia. 2016;110:166-72.

11. Wang F, Wu LH, Li LF, Chen SY. Monotropein exerts protective effects against IL-1 $\beta$-induced apoptosis and catabolic responses on osteoarthritis chondrocytes. Int Immunopharmacol. 2014;23:575-80.

12. Shin JS, Yun KJ, Chung KS, Seo KH, Park HJ, Cho YW, Baek NI, Jang D, Lee KT. Monotropein isolated from the roots of Morinda officinalis ameliorates proinflammatory mediators in RAW 264.7 macrophages and dextran sulfate sodium (DSS)-induced colitis via NF-kB inactivation. Food Chem Toxicol. 2013;53:263-71. 
13. Zhang JH, Xu YM, He YQ, Song HT, Du J, Zhang QY. Study on determination and extraction of iridoid glycosides from Morinda officinalis. $J$ Pharm Pract. 2017:35:328-33.

14. Li C, Dong J, Tian JC, Deng ZP, Song XJ. LC/MS/MS determination and pharmacokinetic study of iridoid glycosides monotropein and deacetyl asperulosidic acid isomers in rat plasma after oral administration of Morinda officinalis extract. Biomed Chromatogr. 2016;30:163-68.

15. Ganzera M, Sturm S. Recent advances on HPLC/MS in medicinal plant analysis-an update covering 2011-2016. J Pharm Biomed Anal. 2018;147:211-33.

16. U.S. Food and Drug Administration, Guidance for Industry, Bioanalytical Method Validation, 2013. https://www.yumpu.com/en/document/view/ 21736056/bioanalytical-method-validation-guidance-for-industry-draftguidance-2013.

17. European Medicines Agency, Guideline on Bioanalytical Method Validation, 2012. https://www.ema.europa.eu/documents/scientific-guideline/guidelinebioanalytical-method-validation_en.pdf.

18. Franconi F, Campesi I. Sex impact on biomarkers, pharmacokinetics and pharmacodynamics. Curr Med Chem. 2017;24:2561-75.

19. Wang YL, Huang SJ, Chi DJ, Li Q, Lei HM, Cui HM. Study on stability of main iridoid glucosides from Morinda officinalis radix. China J Exper Tradit Med Form. 2011;17:65-8.

20. Parquet M, Metman EH, Raizman A, Rambaud JC, Berthaux N, Infante R. Bioavailability, gastrointestinal transit, solubilization and faecal excretion of ursodeoxycholic acid in man. Eur J Clin Investig. 1985;15:171-8.

21. Zhou H. Pharmacokinetic strategies in deciphering atypical drug absorption profiles. J Clin Pharmacol. 2003:43:211-27.

22. Ogungbenro K, Pertinez $\mathrm{H}$, Aarons L. Empirical and semi-mechanistic modelling of double-peaked pharmacokinetic profile phenomenon due to gastric emptying. AAPS J. 2015;17:227-36.

23. Chen TJ, Wang W. Morinda officinalis extract repairs cytoxan-impaired spermatogenesis of male rats. Zhonghua Nan Ke Xue. 2015;21:436-42.

24. Song B, Wang FJ, Wang W. Effect of aqueous extract from Morinda officinalis F. C. How on microwave-induced hypothalamic-pituitary-testis axis impairment in male Sprague-dawley rats. Evid Based Complement Alternat Med. 2015;2015:1-9.

25. Zhang ZQ, Yuan L, Zhao N, Xu YK, Yang M, Luo ZP. Antidepressant effect of the ethanolic extracts of the roots of Morinda officinalis in rats and mice. Chin Pharm J. 2000;35:739-41.

26. Sun YL. Study on the genotoxicity of Panax, Atractylodes, and Morinda. Master Thesis of Sichuan University 2003. Sichuan Province, China.

Ready to submit your research? Choose BMC and benefit from:

- fast, convenient online submission

- thorough peer review by experienced researchers in your field

- rapid publication on acceptance

- support for research data, including large and complex data types

- gold Open Access which fosters wider collaboration and increased citations

- maximum visibility for your research: over $100 \mathrm{M}$ website views per year

At $\mathrm{BMC}$, research is always in progress.

Learn more biomedcentral.com/submissions 